\title{
Solar Greenhouse as an Energy Alternative Solution for Growing Vegetable in High Altitude Region: A Case of Baragaon, Mustang
}

\author{
Dip Pandey \\ Tribhuvan University, Institute of Engineering, Pulchowk Campus, Department of Architecture and Urban Planning, \\ Lalitpur, Nepal \\ Corresponding Email: dipdutt.214@gmail.com
}

\begin{abstract}
:
In cold and dry high desert climate such as in Mustang, Manang or Dolpa growing green vegetables is a challenging task despite solar radiation throughout the whole year. Harsh and snowy winter, turbulent wind, limited availability of arable lands and water impedes plant growth. Solar greenhouse (SGH) is a renewable energy-based alternative for growing vegetables in these zones round the year in surplus quantity. At present, a large quantity of vegetables is purchased from nearby market towns (Pokhara and Beni) at double the price. Promotion of greenhouse vegetable farming has not only potential to relieve local people from such financial burden but can even create new business opportunities. As vegetables produced at these altitudes use only organic manure, their quality is desirable for a market where demand for organic products is constantly increasing.

From a literature study of SGH cases in Ladakh, Humla and Khumbu region it was found that varieties of vegetables could be grown even during winter when temperatures drop to $-25^{\circ} \mathrm{C}$. For instance, owners of specially designed SGHs in Ladakh ate eight times the volume of vegetables they had eaten prior to acquiring these SGHs and have seen their incomes rise by $30 \%$.

The following article presents a study on SGH possibilities for vegetable farming in the Baragaon rural municipality of Mustang district, applying methods such as observations, informal interviews and stakeholder inclusion. Currently, there exists only rudimentary samples of plastic greenhouses in most villages, where only green leafy vegetables grow during winter. During summer, vegetable growth is conducted in open fields rather than inside the greenhouses. This is mainly due to their overheating caused by lack of ventilation. In Chhengor, one of the villages in Baragaon, organic farming is already taking a promising leap towards organic vegetable business. After discussion with farmers and other stakeholders appropriate design of SGH seems a good solution for durability of SGH structure and to ensure that varieties of vegetables grow in surplus quantity round the year. The article presents possibilities for SGH design and discuses factors for SGH establishment such as affordability, monitoring and maintenance. Additionally, it pinpoints infrastructural support such as agriculture policy at local level, for example in forms of subsidies and training of farmers to grant successful implementation of SGH approaches for high altitude settlements.
\end{abstract}

Keywords: Solar Greenhouse, Solar Energy, Organic Vegetables, Entrepreneurship, Small-Scale Farmers

\section{Introduction}

\subsection{Background}

There are various sources from which human society has been harnessing energy. A critical juncture in the history of energy use was Industrial revolution which led to energy intensive societies and city life. Industrial development paid little attention on how energy was extracted and what impact it exerted on environment. Resources were exploited for granted without considering that it would exhaust. Since 1960s, questions about impact of human activities on nature have been raised. Experts began to think about sustainable production and consumption and warned that earth had a limited supply of physical resources and that exceeding the limits could end in catastrophe.
Brundtland Commission [1] acknowledged tension between economic growth and environmental protection, necessity to apply integrated, sustainable solutions to a broad range of problems related to population, agriculture and food security, biodiversity, energy choices, industry and published a report expressing belief that social equity, economic growth and environmental maintenance are simultaneously possible, thus highlighting the three fundamental components of sustainable development, the environment, the economy, and society, which is now known as the triple bottom line of sustainability. It concluded that economic growth was essential, particularly in the developing world, but that there should be a switch to 'sustainable development', which would be environmentally sound [2]. Thus, the commission stated "Humanity has the ability to make development sustainable - to ensure that it meets the needs of the 
present without compromising the ability of future generations to meet their own needs" [1].

Sustainable Development Goal (SDG) 2 states, 'end hunger, achieve food security and improve nutrition and promote sustainable agriculture.' To achieve this goal eight targets have been set - sufficient food for all, healthy nutrition, strengthen small scale farmers, sustainable food production, biodiversity of cultivated plants and livestock, enhance agricultural productivity, open agricultural market and stable food prices. The aims are to double the agricultural productivity and incomes of small-scale food producers, ensure sustainable food production systems and implement resilient agricultural practices that increase productivity and production, increase investment in rural infrastructure and technology development to enhance agricultural productivity capacity by 2030 [3].

Solar energy can be used for various purposes. It is a vital source of energy for life (both plant and animals) on earth. It is in presence of solar energy that plants convert atmospheric carbon dioxide into food and release oxygen. Solar energy is the basis for farming in addition to moisture and minerals, obtained from soil. Climatic condition of a place is critical for this to happen. Plants cannot thrive in adverse climatic conditions unless the environment is controlled. In a cold and dry desert climate such as in Mustang, Manang or Dolpa growing green vegetable is challenging task. Although these places receive solar radiation throughout the year, harsh winter, limited availability of arable lands and water and very cold nights are unavoidable obstacles. One of the ways to combat this problem is by farming in SGH that wisely uses solar energy to create controlled environment that prevents plants from harsh wind and coldness.

Fresh green vegetables are not readily available in high altitude regions. In places where tourist flow is significant, fresh green vegetables may be supplied from lower regions, but places that are not tourist destinations don't receive such supply. So, lack of fresh green vegetables may result in nutritional deficiency.

In order to create suitable environment for growing fresh green vegetable in high altitude climate $\mathrm{SGH}$ is a viable alternative. Adoption of this simple, passive technology can ensure food security, enhance agricultural productivity, strengthen small scale farmers and address problem of nutrition.

\subsection{Need and Importance}

Micro level development initiatives like SGH are necessary to uplift livelihood in rural areas. SGH can produce sufficient fresh green vegetables even in harsh climate, limited arable land and water in high altitude regions. SGHs increase productivity and they can be built at household level so that not just the household demand of green vegetables but surplus quantity can be produced. Adoption of SGH contributes to achieve targets set under SDG 2, therefore this project is necessary.

This project is important since it is related to sustainable agricultural practices, food security, health and nutrition. This project anticipates to increase agricultural productivity and strengthen small scale farmers. The community of project area have health and economic benefit by adopting SGH. It can strengthen social sustainability as well as environmental and economic sustainability.

\subsection{Problem Statement}

In a mountainous region, agriculture is difficult due to steep slopes and soil condition besides long and harsh winter reduces the growing season for fresh vegetables to just three or four months per year. Moreover, lack of road infrastructure and mountainous terrain makes it prohibitively expensive or impossible to import additional supplies. Some food aid is provided by international agencies, but in recent times has been reduced due to rising regional food and fuel prices. As a result, the people living in this region experience high levels of chronic malnutrition and micro-nutrient deficiencies [4]. Much intervention is necessary in order to strengthen social, environmental and economic sustainability of the place.

Despite availability of abundant and perpetual resource in form of solar energy, mountainous region in Nepal are less developed that other regions. It has the potential to benefit from renewable technology to overcome many of its problems. Limited implementation of technological advancement is a big drawback. Had people in such resource endowed region been able to wisely utilize technological advancements, the region would have made huge progress.

Affordability is yet another factor that determines if people in this particular region will be able to adopt advocated technology like SGH. It is not only an issue of financial affordability, but the tedious task of obtaining necessary materials like UV protected plastic sheets which are only available in distant big market in cities like Kathmandu. A few well to do houses may avail of such service but for larger mass of the region it can prove to become a close to impossible task. It is essential in such situation that the design of SGH incorporate locally available material as far as possible. 


\subsection{Purpose}

The main objective of this paper is to achieve food security, improve nutrition and promote sustainable agriculture in high altitude region by building energy efficient SGH that can combat extreme cold, snowfall and wind turbulence for vegetable farming. SGH ensures yearround production of varieties of fresh/green vegetables in surplus quantity for better food and income of the village in high altitude region. The specific objectives are:

- To study if and in which way this is needed in the first place,

- To incorporate locally available material and human resource in the design of SGH,

- To build capacity of local people by transfer of technology and promote people's participation in the project,

- To ensure food security, meet nutritional requirements and promote sustainable agricultural production

\section{Literature Review}

\subsection{Introduction to Solar Green House}

Greenhouse cultivation has evolved from simple covered rows of open-fields crops to highly sophisticated controlled environment agriculture (CEA) facilities that projected the image of plant factories for urban farming. A greenhouse is a covered structure that protects the plants from extensive external climate conditions and diseases, creates optimal growth microenvironment, and offers a flexible solution for sustainable and efficient year-round cultivation [5].

Greenhouses reduce heat losses and increase useful solar gains on a daily and seasonal basis. The passive elements of the greenhouse are a mass storage wall located on the north side and a network of earth-to-air heat exchangers buried in the greenhouse. An air temperature range of 10 ${ }^{\circ} \mathrm{C}-32^{\circ} \mathrm{C}$ is suitable for growing most crops in a greenhouse and soil temperatures between $7{ }^{\circ} \mathrm{C}-24^{\circ} \mathrm{C}$ for germination of cold season crops [5].

Greenhouses of all types are being used in remote mountain areas for crop protection, season extension, seedling production, and growth promotion. Most of these are basic constructions, similar to the plastic-covered tunnel structures used in temperate climates but often using local materials such as bamboo for the frame. SGHs, however, are much less common. These are structures designed to maximize the entry and storage of solar energy to moderate excessive temperature swings, particularly through the use of thermal mass and nighttime insulation. SGH are being successfully demonstrated and disseminated in the cold regions of Asia [6].

Groupe Energies Renouvelables, Environnement et Solidarités (GERES), in partnership with the Ladakh Environment and Health Organization (LEHO) has built 600 greenhouses that allow villagers to grow vegetables throughout the year even when temperatures drop to $25^{\circ} \mathrm{C}$. Owners of these greenhouses eat eight times the volume of vegetables they ate prior to acquiring these greenhouses and have seen their incomes rise by $30 \%$ [7].

The basic greenhouse is $4.5 \mathrm{~m}$ wide and $9.7 \mathrm{~m}$ long. The south-facing wall is glazed with ultraviolet (UV) resistant polyethylene sheets. It is covered at night with straw mats to retain the heat within the structure. In summer, glazing panels can be removed to exhaust excess heat through vents in the walls, which are made from 2 layers of mud brick and a straw-filled cavity to reduce heat losses. The rear and west-facing walls are painted black to increase the heat absorption. The roof is constructed of native willow and poplar logs. Although individual results vary, the performance of the greenhouses has extended the growing season by a minimum of 4 months, with vegetables such as spinach, coriander, and carrot being cultivated in the winter season. Inside the greenhouse, even when outside temperatures reach $-20^{\circ} \mathrm{C}$, the internal air temperature has been maintained above freezing [6].

\subsection{Principles of Solar Greenhouse}

A passive SGH is designed to trap enough solar radiation for the photosynthesis process and to provide the interior climatic conditions required for growing vegetables all year round. When the outside conditions are very cold, heat is stored during the day in the ground and walls of the greenhouse and released during the night to keep the greenhouse air warm. During winter, the greenhouse traps enough energy during the day to ensure that the vegetables do not freeze at night. The temperature variation between day and night should be minimized to reduce thermal stress to the plants. Overheating during the day can be prevented using natural ventilation for cooling, regulated by manually operated shutters. Ventilation also regulates the humidity and thus helps to limit diseases and pests [8]

Stauffer [8] states three main components in a passive SGH:

-Walls on the east, west, and north sides where amount of incident solar energy is limited. These walls are either buried into a hillside or insulated to limit heat loss and increase thermal storage. 
- A polythene sheet set at an angle on the south side, and supported by a wooden frame, which picks up the largest amount of solar energy. The polythene transmits the majority of incident solar radiation into the greenhouse. This warms interior space and is absorbed by vegetables, ground, and the walls. The sheet can be covered with a moveable layer of insulation like a curtain, cloth or mat after sunset to reduce night time heat loss.

- A (solid) roof on the north side to limit heat loss. The roof is tilted to avoid shading in winter and reduce interior volume.

\subsubsection{Collection of Solar Radiation}

Solar radiation is taken up through a transparent polythene sheet covering the south face of the greenhouse. The angle of the polythene is calculated so that the maximum amount of solar radiation is transmitted into the interior. The angle of the lower section of the polythene is $50^{\circ}$ or more (measured from the horizontal) - the best angle to transmit solar radiation is in the early morning or late afternoon when the sun is low in the sky. The angle of the upper section is $25^{\circ}$ or more (measured from the horizontal) - the best angle to transmit the mid-day solar radiation and allow small amounts of snow to slide off. Moveable insulation (parachute, cloth) is used as a curtain below the polythene after sunset to reduce heat loss; it is removed after sunrise. Moveable insulation can increase the ground and interior temperature at night by up to $5^{\circ} \mathrm{C}$. At high altitudes, a double polythene layer can be used to reduce heat loss; it can also increase the interior temperature by up to $4^{\circ} \mathrm{C}$ at night [8].

\subsubsection{Thermal Storage and Insulation}

Stauffer [8] explains following components used in the design to increase thermal storage and reduce heat loss:

Double wall: The walls are composed of three layers: an outer load-bearing wall built with mud brick, rammed earth, or stone; an inner wall used to store heat during the day and release it at night, also built with mud brick, rammed earth, or stone; and an insulating layer of materials like straw, sawdust, wood shavings, dry leaves, dry grass, or wild bush cuttings pressed between the two.

Color: The inner side of the west wall is whitewashed to reflect the morning solar radiation after the coldness of the night; the inner side of the east wall is painted black to absorb and store the afternoon solar radiation, which is then released at night to heat the interior space; and the bottom two feet of the inner side of the north wall are whitewashed and the upper part painted black for similar reasons.
Roof: The fixed roof is sloped (to the north) at an angle of $35^{\circ}$. In winter, when the sun has a low elevation angle, this angle optimizes the solar radiation absorption on the inside surface. During summer, when the sun is high in the sky, the roof partly shades the greenhouse and reduces the risk of overheating. The roof is covered with a layer of insulation (straw, or similar); a piece of white cloth or parachute material can be added below it to improve the insulation and reflect solar radiation onto the vegetables. The shape of the roof reduces the interior volume compared to traditional greenhouses, thus increasing the interior temperature.

Ground: The greenhouse floor is dug out so that it lies 6" $(15 \mathrm{~cm})$ below the outside surface level. This improves plant growth as the dip acts as a trap for carbon dioxide, as well as providing additional thermal insulation. In extremely cold climates, a 2" layer of dung should be laid four inches below the surface to insulate the ground and increase the thermal mass efficiency. Horse or donkey dung are the most suitable as they contain straw, but yak or cow dung can also be used.

Door: The door is located on the wall opposite to the side from which the prevailing wind blows (the lee side) to reduce infiltration of cold air.

Ventilation: On sunny days, the air in the greenhouse can become very warm. Overheating (over $30^{\circ} \mathrm{C}$ ) can damage the vegetables and encourage diseases and pests. Manually operated openings (ventilators) are provided in the lower part of both sides (door, wall shutter) and in the roof. The warm air rises and leaves the greenhouse through the roof ventilator, drawing in the cooler ambient outer air through the lower ventilators.

\subsection{Principles of Site Selection}

Stauffer [8] suggests following three criteria for site selection:

Water supply: Vegetables require water to grow. During the cold winter period, the greenhouse requires less ventilation, evaporation is lower, and more moisture is retained inside, thus only a small amount of water is required. But in spring and summer, the greenhouse is ventilated during daytime to avoid overheating, evaporation is higher, and moisture is lost with the ventilated air, so that a larger amount of water must be given. During winter and spring, many streams and springs are frozen; it is necessary to ensure that there is a source of running water located close enough to the greenhouse so that transportation is not so difficult as to discourage the farmer from operating the greenhouse. The 
crucial period is spring, when more water is required than in winter but static sources may still be frozen. The distance to the nearest running water has to be acceptable during this period. The maximum distance that a farmer can be expected to carry water without it becoming a disincentive is about 600 feet $(200 \mathrm{~m})$ in winter and 300 feet $(100 \mathrm{~m})$ in spring and summer.

Solar radiation: Solar radiation is required both for photosynthesis and to heat the greenhouse. If the sunrise is too late or the sunset too early, the greenhouse remains cold for longer and vegetable production is reduced. Nearby obstacles can also shade the greenhouse. Sunrise before 9:30 am and sunset later than $3: 00 \mathrm{pm}$ is suitable condition.

Slope and type of land: The slope of the land influences the amount of solar radiation collected, the ground temperature, and the heat loss through the walls. A site is suitable if the land is flat and dry. In lands on a southfacing slope, the amount of solar radiation is increased by the ground reflection, at the same time, the greenhouse is partly underground, the ground is warmer than the ambient air, and heat loss through the walls is reduced. The advantage of a land that backs on to a south-facing terrace (the drop down from one terrace to the next forms the back of the site) is that the terrace wall can be used as the back wall of the greenhouse and may support the roof; the benefits are a lower investment cost, warmer ground, and a larger thermal mass if the step is built up using stone masonry.

\section{A site is rejected if}

- the land is on a north-facing slope the amount of solar radiation is decreased

- the land is against a north-facing terrace: the greenhouse has to be oriented towards the north and the benefits will be limited

- the land is marshy: the ground freezes easily in winter and the vegetables may also freeze

- the site is not on agricultural land (stone, sand, or similar)

\subsection{Energy Requirements for Plant Growth}

Plants use the energy in sunlight to convert $\mathrm{CO}_{2}$ (from the air) and water (from the soil) into sugars - a process called photosynthesis. The sugars are used to metabolize and to build new stems and leaves and when plants burn their sugars for food. $\mathrm{CO}_{2}$ is produced as a waste product. Since photosynthesis is powered by sunlight, plants absorb more
$\mathrm{CO}_{2}$ than they give off during the daytime, but at night, when photosynthesis is dormant, the opposite occurs.

Carroll and Duss [9] explain that greenhouse uses a few basic scientific principles to maintain its interior microclimate. Sunlight is the primary source of heat for a passive SGH. Sunlight passes through transparent materials, such as glass or clear plastic and when it hits an opaque, or less transparent surface, some of that light is transformed into heat. The darker the surface, the more light gets transformed into heat.

In most traditional greenhouses comprised of glass or plastic, there is almost always some heat loss which requires additional heat sources to maintain acceptable temperatures during colder periods. The goal is to trap energy inside the greenhouse to comfortably heat the plants, the ground, and soil inside it. Ideally, the air near the ground is warmed and prevented from rising and dissipating too quickly. In order for plants to flourish, a SGH must provide the appropriate amounts of light, humidity, and warmth and the key to operating an effective SGH is being able to maintain a reasonably stable climate to support plants [9].

Carroll and Duss [9] explain that air movement also has a large impact on the morphology, physiology, and reproduction of the plants as it affects the temperature of the leaf, gas exchanges and resistance of the boundary layer and, therefore, photosynthesis, transpiration and water use. Limited air movement, for example, hinders the supply of $\mathrm{CO}_{2}$ to the stomata of the leaves for photosynthesis. Therefore, it is necessary to achieve a minimum horizontal air movement for $\mathrm{CO}_{2}$ supply to the leaf stomata. Increases in $\mathrm{CO}_{2}$ levels generate an increase in photosynthesis and subsequent increase in yield as well as induces an improvement in the water use efficiency. The recommended $\mathrm{CO}_{2}$ concentration depends on the species and variety, as well as the environmental conditions. For vegetables, it has been recommended not to exceed $1500 \mathrm{ppm}$ for cucumber or $1000 \mathrm{ppm}$ for tomato and pepper. Recently, $1000 \mathrm{ppm}$ has been considered a suitable maximum limit for all species except cucumber, aubergine, and gerbera. An excess in $\mathrm{CO}_{2}$ in tomato plants may cause abnormally short leaves or the rolling of the leaves, whereas in other crops it may cause leaf chlorosis. Ventilation is the most economic method to limit $\mathrm{CO}_{2}$ depletion in the greenhouse air; however, in most contemporary systems it only allows the maximum to reach ambient conditions (350-400 ppm).

During the day (photosynthesis), plants generally use twice as much $\mathrm{CO}_{2}$ than they give off from cellular 
metabolism. After the photosynthetic period, plants continue respiring and give off $\mathrm{CO}_{2}$ without using any, so that there can be a buildup above ambient levels overnight in a well-insulated greenhouse for the start of photosynthesis the next morning. Thus, there is a delicate balance between maintaining proper $\mathrm{CO}_{2}$ concentrations and temperatures within the greenhouse. To date, the most effective way to maintain control over the internal greenhouse $\mathrm{CO}_{2}$ concentrations has been via the application of pure $\mathrm{CO}_{2}$ combustion gases, enrichment with small burners, or enrichment from a central boiler. However, these methods are expensive and wasteful [9].

\section{Methodology}

The study was approached through literature study and qualitative research strategy of ethnography and as its outcome, a project was planned and analyzed using logical framework approach. The proposed case area is Baragaon rural municipality, Mustang.

In ethnographic research, in-depth engagement with sitespecific settings is emphasized, most especially through active and thorough observation [10]. Key informant interview is also a research tool in ethnography; however, it is not possible to access all aspects of lived experience in interviews. Despite wishes to collaborate, informants in many occasions either hesitate or cannot talk about certain topics. In such situation a new research tool, mobile ethnography can be used to capture interpretations, experiences and actions of subjects in research case area which helps overcome the limitations of conventional ethnography. Mobile ethnography pursues relationships and connections, follows unpredictable trajectories and traces cultural formations in its pursuit of explanations beyond borders. It invokes a sense of voyage, where the ethnographer traces clues by travelling along pathways, spatially, temporally, virtually, or bodily [11]. This paper explores the idea of SGH for vegetable farming in high altitude region by travelling virtually to places where SGH has been successfully implemented. The study then explores feasibility of SGH by travelling spatially and temporally through number of villages in Mustang talking to people about their knowledge on $\mathrm{SGH}$, its scope and expectations.

As an outcome, a project is presented in form of a Logframe Matrix after logical framework analysis (LFA). LFA is an analytical, presentational and management tool which can help planners and managers analyze the existing situation during project preparation, establish a logical hierarchy of means by which objectives will be reached, identify some of the potential risks, establish how outputs and outcomes might best be monitored and evaluated and present a summary of the project in a standard format [12].

\section{Data Set and Analysis}

\subsection{General Information}

Baragoan Gaupalika in Mustang District includes Kagbeni, Khinga, Jharkot, Muktinath, Chhengur, Jhong, Putak, Purong, Lubra, Tiri, Chhusang and Tetang. The total area of the gaunpalika is 886 sq.km. According to CBS, 2011, population of the gaunpalika was 2330 and population density is 3 people per sq.km. The case area is sparsely populated. According to records of DHM, extreme minimum and maximum temperature were -11.6 ${ }^{\circ} \mathrm{C}$ (17 Jan, 1996) and $33.33{ }^{\circ} \mathrm{C}(10,11$ June, 1989) respectively. The latest records show that maximum and minimum temperatures in June 2017 were $27.7^{\circ} \mathrm{C}$ and $10.5^{\circ} \mathrm{C}$ respectively. Similarly, in December 2017, minimum and minimum temperature were $20.5^{\circ} \mathrm{C}$ and $4.5^{\circ} \mathrm{C}$ respectively.

\subsection{Observation}

Many rudimentary samples of greenhouses were found in different villages in Mustang. Such greenhouses were built up of timber structure covered with plastic sheets on all sides and roof. The plastic sheet on one of the sides were cut in form of a door for access inside the green house. There was no provision of ventilation which caused overheating and plants turned yellow. Condensation under the roof was another problem observed in most of the cases. In Marpha, Jhong and Putak, the greenhouses were not in much use. Many of the farmers claimed that during summer, vegetable grew naturally in open fields and controlled environment was not necessary. Such a control was necessary during winter, but in conventional greenhouses only green leafy vegetables could grow. The quantity of vegetables produced was just enough for household consumption and therefore the activity was limited to subsistence. The owners of conventional greenhouse were unable to produce surplus and question of creating business out of vegetable production irrelevant.

An improved sample of solar green house was built in Syang, a neighboring village near Jomosm, where vegetables were produced at commercial scale and supplied to the market. The greenhouses were built under High Mountain agro-business and livelihood improvement project of Nepal Government. There were seven greenhouses built up of stone masonry wall, fiber 
sheet roof and it also had provision of lateral ventilation. The roofing structure was made up of timer rafters. Varieties of vegetable were growing e.g. cabbage, cucumber, brinjal, beans, etc.

In Chhengur, a village in Baragaon rural municipality, an enthusiast and hardworking farmer was undertaking organic farming. The farmer owns two greenhouses although conventional ones of which one is eight years old and another only two years. Even after eight years the plastic sheet was intact. But main problem was with timber posts that gets rotten despite precautionary measures by wrapping plastic sheet. The famer had made investments in purchasing essential equipment like grass cutter.

\subsection{Summary of Interviews}

Respondent were univocal about the potential of villages in Mustang in producing organic vegetables. All of them stressed the use of organic manure in form of animal waste mixed with dried pine leaves. In earlier days they used dried leaves of red-cedar (dhupi), but due to provisional restriction in community forests the use shifted to pine leaves. The use of SGH was not effective. They were not well aware about better way to construct SGH. Although construction of a transparent enclosure creates greenhouse effect and indoor temperature is higher than outdoor it also creates other problems like condensation and overheating. The village farmers were also not well aware about the crop cycle. But some of them responded that vegetables planted two months before winter matures during winter and they were able to consume that. Some of the farmers also shared that root vegetables like radish would not be plucked from ground even after maturity so that it can be preserved for consumption during winter.

There was also a practice of drying vegetables and meat for consumption during winter. The food habits of people consisted of buckwheat, oats and dried meat. Respondents said that vegetables were brought from Beni and Pokhara. The cost almost doubled when it reached Mustang. On the other hand, they also said that some products like potatoes and apple were highly valued in the nearby town markets.

Entrepreneurship from vegetable farming was taking a promising development in Syang and Chhengur. The farmer in Chhengur said that elsewhere like in Jhong and Putak people were not taking care of SGH and it actually looked uncared. In Chhengur, however, the farmer was making a profitable income from vegetable business. The farmer showed his concern on organic farming and its impact on local market and prospects of reaching faraway markets as well. The farmer had taken trainings related to farming and also participated in agro-exhibitions in Pokhara. The officer at District Agriculture Development Office (DADO) also confirmed that the farmer in Chhengur was an exemplary. There were also concerns regarding youths. Most of the youths migrate to cities and abroad for better living standards. This was cited as a pressing issue in development of not just vegetable farming but the overall development of the place.

The farmers anticipated subsidy in form of financial benefit and technical support for new projects like SGH. In Jhong, a resident was already undertaking production of CSEB. Taking this as an example other people could undertake other kinds of entrepreneurship like SGH or cold storage. The commonly grown vegetables these days were cabbage, green leafy vegetables (broad leaf mustard, swiss saag), tomato, carrot, cucumber, brinjal, zuchhini, beans, capsicum etc.

Year ago, when there was no road connection to Mustang, people were unaware about how to eat certain types of vegetables. For example, people would peel of leaves of cabbage one by one and not find anything at last. There was also a superstition that growing garlic would kill people. But with time these beliefs are gone. At present, garlic and cabbage are two of the common vegetables in the region. A respondent shared that once a single cabbage weighing $25-30 \mathrm{~kg}$ was produced. The SGH were constructed by the farmers themselves without any technical assistance.

\subsection{Logical Framework Analysis}

\subsubsection{Participant Analysis}

Stakeholder Mapping: Villagers, local government, schools, consumers in nearby towns, contactors and neighboring villages were identified as stakeholder with different roles in this project. Villagers and local government are the key stakeholders. The villagers will build energy efficient SGH and produce organic vegetable round the year in surplus quantity whereas local government will provide technical and financial support in addition to monitoring and evaluation. NGOs and schools can influence the project by creating awareness or working as social mobilizer. The contractors can supply surplus production of organic vegetables to nearby towns thus reversing current supply direction. The local hotels and potential buyers in nearby towns will then benefit from consumption of organic vegetables. For the neighboring villagers, practice of growing organic vegetable inside SGH will be an exemplary lesson. 
During winter vegetables (non-organic) are supplied from Pokhara and Beni and the cost almost doubles when it reaches local or hotels in Mustang. If they could afford $\mathrm{SGH}$, organic vegetables can be grown during winter in surplus quantity. The villagers use only organic manure (mix of animal waste and dried pine leaves) for growing vegetables. The product can be supplied to nearby markets. There is a potential to develop local entrepreneurship. However, it is necessary to build energy efficient SGH and develop link between local and city market. Villagers are willing to build SGH and expect a subsidy provision and soft loan. Locally available materials and manpower can be incorporated.

SGH should be designed to overcome extreme cold and wind turbulence of the region. The technicians and officials at DADO and Gaunpalika Agriculture Division (GAD) can play the role of implementers and monitor and evaluate the project. According to DADO, it is necessary to develop contextual and climate responsive SGH through research and development. Involvement of academic institutions is also required.

\subsubsection{Problem Analysis}

The core problem is dependence for vegetables, compromise in nutrition and ad-hoc agricultural practices. The main reason for this problem is limited quantity and varieties of organic, fresh and green vegetables produced in the villages and only during summer season. Only rudimentary sample of solar greenhouse were found in the villages that lacked provision of ventilation. Such samples were built with locally available timber, Bhote peepal, as main structure and a transparent plastic sheet as side walls and roof. Many respondents reported that irrigation was a problem during dry season. As a subsidy, DADO provides only plastic sheets to the villages.

This problem has multiple effects, firstly expensive and non-organic vegetables that is supplied from nearby towns. The scope of small-scale farmers is also limited. They have not been able to develop entrepreneurship at local level with vegetable production. Due to limitation in material and technology availability, partial subsidy provision and limited knowledge on appropriate design of $\mathrm{SGH}$, the villagers are unaware about the benefits of climate responsive SGH. A prototype of such SGH needs to be demonstrated for the benefit of the villager with regards to its design and construction and additionally also on how to grow vegetables inside SGH.

\subsubsection{Objective Analysis}

The goal of this project is to achieve food security, improve nutrition and promote sustainable agriculture. The purpose is to ensure year-round production of varieties of organic, fresh and green vegetables in surplus quantity for better food and income. To meet this purpose the project needs to build energy efficient solar green house, plastic ponds for snow harvesting for irrigation, seed bank for preserving plants of local variety and availability of organic / compost manure.

With successful implementation of this project it is expected that the local business will develop, small scale farmers' capacity to grow and sell vegetables will be strengthened. With activities like design of site specific SGH and training on organic vegetable farming in SGH and training on construction of SGH the above-mentioned outputs can be obtained.

\subsubsection{Alternative Analysis}

After analyzing the probable projects based on cost, chance of success, time horizon, social risk and sustainability, Solar Greenhouse was the most viable option.

\subsubsection{Project Elements}

Goal: Achieve food security, improve nutrition and promote sustainable agriculture

Purpose: To ensure year-round production of varieties of fresh/green vegetables in surplus quantity for better food and income of the village.

Output: Develops local entrepreneurship, strengthens small-scale farmers, builds capacity to undertake organic farming inside SGH and learn about repair/maintenance of SGH

Activities: Training on Organic Vegetable Farming inside SGH, Design and Construction of Site Specific SGH

Input: Revise subsidy policies in agriculture, $\mathrm{R}+\mathrm{D}$ of greenhouse for vegetable farming, promote alternative material production at local level (e.g. CSEB at Jhong), consultation and supervision, monitoring and evaluation

\subsubsection{Establishing the indicators}

The achievement of hierarchy of objectives are known by following indicators. The goal is achieved if:

- Supply from other areas is reduced

- Increase in number of SGH

- Demand from nearby towns

The purpose is met if varieties of vegetables grow during winter (Dec/Jan) also. 
The outcome can be measured in terms of:

- Vegetables supplied to local hotels / shops and nearby towns

- Rise in Income of local farmers

- Participation of local people in Training activities and application of lessons learnt

People's Participation, setting up of workshops related to construction and inputs from experts (Architects/ Engineers) are objectively verifiable indicators for project activities.

Similarly, release of subsidy or soft loan is an indicator for required project input.

\subsubsection{Determining Assumptions}

The concept of assumptions and risks applies at all levels of the design summary. Assumptions and risks complete the cause-effect logic of the LFM. The completion of the activities will result in the outputs only if certain assumptions hold true and the risks do not eventuate. This applies in the same way to the project outcome and the intended impact, which will only be achieved if assumptions hold true and the risks do not eventuate.

There are political, social, financial, environmental, institutional, and climatic factors that influence project which are outside direct control of project management. Assumptions are positive statements of conditions, events, or actions that are necessary to achieve the results at each level of the LFM. In contrast to this, risks are negative statements of conditions, events, or actions that would adversely affect or make it impossible to achieve the intended results.

If political support for policy revision at local level is forthcoming the project inputs will be implemented. If revised subsidy policy includes provision of partial fund and technical support for $\mathrm{SGH}$, villagers will be able to build climate responsive SGH but there is a potential risk also. SGH is expensive and locals may not be able to afford it, so a soft loan provision is also necessary. Despite construction of SGH, developing entrepreneurship, strengthening small scale farmers and building their capacity to undertake organic farming required support from DADO, potential buyers and vegetable supplying contractors. So only if vegetable supplying contractors cooperate, DADO capability is strengthened for periodic evaluation, monitoring and training and that people participate in training and put lessons into practice, stated outputs of SGH can be acquired. Snowfall and wind are other potential risks. Year-round production of varieties of vegetables if possible only if problem of irrigation during winter and dry season is managed and that indoor temperature, humidity, ventilation and solar gain is conducive for plant growth. But the most important assumption is that with revised subsidy people will be able to afford SGH. Only then the goal of food security, meeting nutritional requirements and promoting sustainable agriculture practice will be partially achieved.

\section{Findings and Discussion}

SGH were found in rudimentary form and its performance in extreme climatic condition was ineffective. Villagers spent Rs. 5,000 for plastic sheets the remaining Rs. 5,000 was provided by DAO. For wood they have to pay about Rs. 5,000 and Labor cost is about Rs. 1,500 per day. The investment is approximately Rs. 20,000. These SGHs have lasted for five years and in some cases for more than eight years.

In Syang village, improved sample of seven SGH of size $11 \mathrm{~m} \times 5.5 \mathrm{~m}$ were constructed for vegetable farming at commercial scale. The total cost was 19,55,181 and share of the owner was 391,036 . The cost of one SGH is approximately 280,000 . This sample is almost fourteen times costlier than the rudimentary samples. However, there is no income from rudimentary samples but from this sample there is a promising monthly income of Rs. 200,000 to Rs. 300,000 . Deducting operation and maintenance cost, investment can be recovered. However, SGH use is limited and number are also few. In addition to growing vegetable, it is also used for drying beans and seeds.

There challenges faced by owners of rudimentary forms of SGH were:

- Rapid decay of wooden post

- Plastic sheet exposed to turbulent wind

- Faster heat gain and heat loss

- Condensation, no ventilation

The villagers also shared the fact that there is a growing demand for organic vegetable from nearby towns. Due to impact of climate change, there is rise in temperature and more rainfall which has reduced duration of winter migration. Moreover, the change is good for growing vegetables. The interest among younger generation in entrepreneurship (Hotels, CSEB) could be extended to include organic vegetable farming for which $\mathrm{SGH}$ is a pertinent option. In Marpha village there is an opportunity for $a+2$ passed student to undertake a yearlong agriculture related Training in Israel. The community bonding is strong in the villages. Both men and women share household and outdoor activities. 
It is not sufficient to provide subsidy for plastic sheets only. Local people are less aware about the appropriate construction technology of SGH. As a result of this, they have been able to build only rudimentary forms of SGH that are neither efficient enough nor appropriate in design as basic principles (e.g. ventilation, orientation, colour, etc.) are also not followed. It is necessary that the subsidy extends to include technical inputs from architects/engineers/ contractors. In doing so, the cost of SGH will be expensive. To make it affordable, it is necessary to provide soft loan. There are multi-purpose and agro cooperative in the village that could co-ordinate to make necessary arrangements. So, building an energy efficient SGH that can produce year-round fresh/green vegetables requires co-ordination among various stakeholders only then will it be affordable.

\section{Conclusion}

At present there are only rudimentary forms of conventional greenhouses in Baragaon and Gharpjhong rural municipality in Mustang. The performance of these greenhouses was not effective. Some of these structures were not in use either. Others were used for drying seeds.
The main problem was the design of the greenhouse itself in relation to size, orientation and material use in addition to absence of double wall, slope of roof, ground conditions, proper door and ventilation.

There is a necessity of building energy efficient SGH in Mustang. The area has a potential to produce organic vegetables and such quality is desirable for a market in nearby cities where demand for organic products is constantly increasing. Moreover, SGH makes surplus production of varieties of vegetable possible throughout the whole year. The local people can benefit from the business opportunity. It should also be noted that food intake of local people can also improve. At present, they depend more on dried vegetables and dried meat. Consumption of fresh green vegetable will improve their nutritional levels.

The farmers have also expressed their interest in building SGH seeing the possibility of growing vegetables in surplus quantity and indicating the business opportunity thereby. Since the area is a tourist destination, current demand of fresh green vegetables is supplied from nearby cities, Beni and Pokhara, but the price doubles. The farmers are aware about the fact that local production can

Table 1: Log-frame Matrix (Project Summary)

\begin{tabular}{|c|c|c|c|}
\hline Project Elements & Indicators & Source of Verification & Assumptions/ Risks \\
\hline $\begin{array}{l}\text { Goal: Achieve Food Security, improve } \\
\text { nutrition and promote sustainable } \\
\text { agriculture }\end{array}$ & $\begin{array}{l}\text { Supply from other areas is } \\
\text { reduced; Increase in } \\
\text { number of SGH; Rise in } \\
\text { demand from nearby areas }\end{array}$ & Project reports & $\begin{array}{l}\text { With provision of Subsidy } \\
\text { people find SGH } \\
\text { affordable }\end{array}$ \\
\hline $\begin{array}{l}\text { Purpose: To ensure year-round } \\
\text { production of varieties of fresh/green } \\
\text { vegetables in surplus quantity for } \\
\text { better food and income of the village }\end{array}$ & $\begin{array}{l}\text { Growth of varieties of } \\
\text { vegetables during winter } \\
\text { (December / January) }\end{array}$ & $\begin{array}{l}\text { Sales Record, Site } \\
\text { Observation, Survey }\end{array}$ & $\begin{array}{l}\text { Problem of irrigation is } \\
\text { managed during winter and } \\
\text { spring. } \\
\text { Risk - Snow and Wind }\end{array}$ \\
\hline $\begin{array}{l}\text { Output: Develops local } \\
\text { entrepreneurship, strengthens small- } \\
\text { scale farmers, builds capacity to } \\
\text { undertake organic farming inside SGH } \\
\text { and learn about repair/maintenance of } \\
\text { SGH }\end{array}$ & $\begin{array}{l}\text { Vegetable is supplied to } \\
\text { local shops/ hotels and } \\
\text { nearby towns. Rise in } \\
\text { Income, Participation of } \\
\text { locals in training activities }\end{array}$ & $\begin{array}{l}\text { Records of Government } \\
\text { offices (Agro-firm } \\
\text { registration), Tax } \\
\text { records, Reports of } \\
\text { trainings }\end{array}$ & $\begin{array}{l}\text { Vegetable supplying } \\
\text { contractors co-operate, } \\
\text { DADO capability is } \\
\text { enhanced to undertake } \\
\text { monitoring and evaluation, } \\
\text { People participate and } \\
\text { practice }\end{array}$ \\
\hline $\begin{array}{l}\text { Activities: Training on organic } \\
\text { vegetables inside SGH, Design and } \\
\text { construction of SGH }\end{array}$ & $\begin{array}{l}\text { People's participation, } \\
\text { Workshop Setup, } \\
\text { Inputs from experts } \\
\text { (Architects/ Engineers) } \\
\text { Involvement of Contractors }\end{array}$ & $\begin{array}{l}\text { Firm Registration, A/E } \\
\text { Designs, Reports and } \\
\text { Drawings, }\end{array}$ & $\begin{array}{l}\text { Subsidy policy is revised, } \\
\text { soft loan is granted and } \\
\text { SGH becomes affordable, } \\
\text { Risk- Investment in SGH } \\
\text { without subsidy or soft } \\
\text { loan may be unaffordable }\end{array}$ \\
\hline $\begin{array}{l}\text { Inputs: Revise subsidy policy, research } \\
\text { and development of SGH, promote } \\
\text { alternative material production at local } \\
\text { level (e.g. CSEB), Consultation, and } \\
\text { Supervision, Monitoring and } \\
\text { Evaluation }\end{array}$ & $\begin{array}{l}\text { Release of Subsidy, } \\
\text { Provision of soft loan, } \\
\text { Involvement of experts, } \\
\text { researchers, professionals, }\end{array}$ & $\begin{array}{l}\text { DADO records, } \\
\text { Research reports }\end{array}$ & $\begin{array}{l}\text { Political support for policy } \\
\text { revision is forthcoming at } \\
\text { local level. }\end{array}$ \\
\hline
\end{tabular}


relieve hoteliers from high price vegetables and in addition the product is not organic either.

It is possible to build energy efficient SGH that can combat extreme cold, snowfall and wind turbulence for vegetable farming in high altitude region, by initiating a project at Chhengor. Such a project is absolutely necessary because it promotes sustainable agricultural practice and ensures food security in the first place. Additionally, it improves the nutritional level of the people as organic, fresh and green vegetables will be available. Locally available materials like timber, stones, and CSEB can also be used in the design of SGH. Use of local materials and provision of subsidy and soft loan makes SGH affordable.

\section{Acknowledgments}

The author is thankful to Prof. Dr. Sushil Bahadur Bajracharya, Prof. Dr. Martina Maria Keitsch and Asso. Prof. Sangeeta Singh for their valuable insights, pertinent feedbacks and comments in the research. Thanks also goes to Mr. Yogi Kayastha from Humal Development Initiative and Ar. Sameer Ratna Bajracharya for sharing their knowledge on solar greenhouses. The author is greatly indebted to Mr. Anup Nainabasti, Officer at DADO, Jomsom and local residents of Mustang especially Mr. Nyima Gurung, Jhong and Mr. Gam Bahadur Gurung, Chhengor. Thanks also goes to MSESSD program for providing the necessary fund to carry out this research.

\section{References}

[1] Brundtland, G., \& Khalid, M. (1987). UN Brundtland commission report. Our Common Future.

[2] Pisani, J. A. (2007). Sustainable development - historical roots of the concept. Environmental Sciences, 83-96.

[3] National Planning Commission. (2017). Nepal's Sustainable Development Goals. Kathmandu: Government of Nepal.

[4] Candy, S., Moore, G., \& Freere, P. (2012). Design and modeling of a greenhouse for a remote region in Nepal. Evolving Energy-IEF International Energy Congress (IEFIEC2012) (pp. 152-160). Elsevier.

[5] Shamsiri, R. R. (2018). Advances in greenhouse automation and controlled environment agriculture: A transition to plant factories and urban agriculture. International Journal of Agricultural and Biological Engineering, 1-22.

[6] Fuller, R., \& Zahnd, A. (2012). Solar Greenhouse Technology for Food Security: A Case Study from Humla District, NW Nepal. Mountain Research and Development (MRD), 411-419.
[7] (2018, April 27). Retrieved from www.alimenterre.org: http://www.alimenterre.org/en/ressource/passive-solargreenhouses-in-ladakh

[8] Stauffer, V. (2004). Theory of Passive Solar Greenhouse for Cold Areas. In V. Stauffer, Solar Green House for the Trans-Himalayas (pp. 8-17). Kathmandu: ICIMOD, GERES.

[9] Carroll, T. N., \& Duus, M. R. (2012). United States of America Patent No. US9554523B2.

[10] Groat, L., \& Wang, D. (2013). Architectural Research Methods. New Jersey: John Wiley and Sons, Inc.

[11] O'Reilly, K. (2012). Multi-Sited and Mobile Ethnography. London, England: Sage Publications Ltd. Retrieved November 12, 2016

[12] Aus AID. (2000). The Logical Framework Approach. Commonwealth of Australia. 